
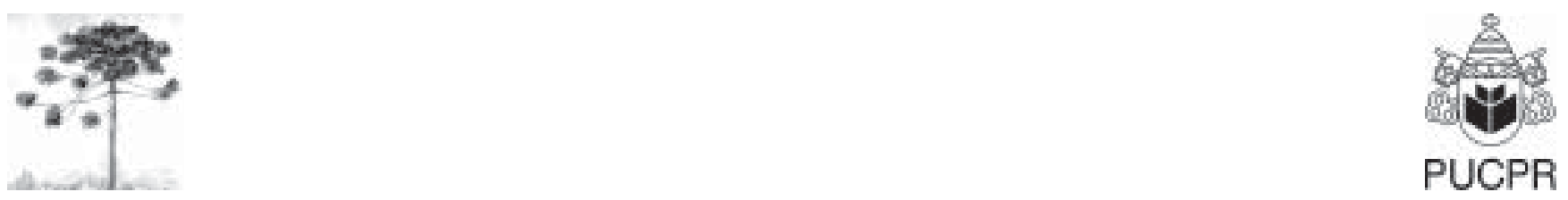

\title{
ASPECTOS HISTOPATOLÓGICOS E HISTOQUÍMICO DE OSTEOSSARCOMAS EM CÃES
}

\author{
H istophatological and histochemical aspects of osteossarcomes in dogs
}

\author{
Anderson Martelli ${ }^{1}$, Leandro BC. Teixeira ${ }^{2}$, Arnaldo R Santos Jr. ${ }^{2,3,4}$ \\ ${ }^{1}$ Aluno do Curso de Ciências Biológicas, Instituto de Ciências Biológicas, Unipinhal. Espírito Santo do Pinhal, SP - Brasil. \\ ${ }^{2}$ D ocenteda Faculdade de MedicinaV Veterinária, Instituto de Ciências Biológicas, Unipinhal. E spírito Santo do Pinhal, SP - Brasil. \\ ${ }^{3}$ D ocente da Faculdade de Ciências Biológicas, Instituto de Ciências Biológicas, Unipinhal. Espírito Santo do Pinhal, SP - Brasil. \\ ${ }^{4}$ D ocente do D epartamento de Biologia Aplicada a Agropecuária, Faculdade de Ciências Agrárias e Veterinárias (FCAV), \\ Universidade E stadual Paulista (Unesp), Jabociticabal, SP - Brasil, e-mail: arsantosjr@ yahoo.com.br
}

\begin{abstract}
Resumo
O steossarcoma (OSA) é um tumor mesenquimal primário maligno cujas células produzem matriz óssea. É um tumor agressivo, de crescimento rápido, e com grande incidência de formação de metástases. 0 diagnóstico é baseado em dados histopatológicos, contudo, não há consenso nos sistemas de classificação desse tumor. D esta forma, nós nos propusemos a fazer uma avaliação histológica e histoquímica de O SAs buscando fornecer informações que possam ser utilizadas para a melhor compreensão da doença. Realizamos um levantamento dos casos de O SA no hospital veterinário do Unipinhal. As amostras obtidas nos arquivos de histopatologia, foram analisadas histoquimicamente com hematoxilina e eosina (HE), azul de toluidina em pH 4,0 (AT), xylidine ponceau em pH 2,5 (X P) e azul alcian em pH 2,5 (AA). A HE, confirmou o diagnóstico de O SA e mostrou uma intensa proliferação celular, além da produção de matriz osteoide. Com o AT, encontramos ao redor das células uma grande quantidade de glicosaminoglicanos, exceto onde se observa osteoide formado. Esses resultados foram corroborados com o AA. Com o XP, detectamos proteínas em toda a região do osteoide. O diagnóstico de OSA se restringe principalmente na análise morfológica do tumor e na produção de matriz extracelular. Rotineiramente, isso é feito por HE. Aqui demonstramos um método rápido e fácil que permite obter mais informações sobre o tumor e sua matriz, facilitando o diagnóstico.
\end{abstract}

Palavras-chave: O steossarcoma; Histopatologia; Histoquímica; Matriz extracelular. 


\begin{abstract}
Osteossarcome (OSA) is a mesenquimal primary malignant tumor whose cells produce bone matrix. It is an aggressive tumor, of quick growth, and with a great metastases formation incidence. The diagnosis is based in histophatology, however there is not consensus in the systems of classification of that tumor. In this way, we proposed do a histological and histochemical evaluation of OSA looking for supply information that can be utilized for the best comprehension of that tumor. We carry out a surch for the cases of OSA in the veterinary hospital of the Unipinhal. The samples obtained in the files of histophatology, were analyzed by histochemical with hematoxilin and eosin (HE), toluidin blue at pH 4.0 (TB), xylidine ponceau at $\mathrm{pH} 2.5(\mathrm{XP})$ and alcian blue at $\mathrm{pH} 2.5(\mathrm{AB})$. With $\mathrm{HE}$, we confirmed the diagnosis of OSA and showed an intense cellular proliferation, beyond the osteoide matrix produced. With TB we find around the cells a large quantity of glicosaminoglicans, except where was observed osteoide formation. Those results were corroborated with AB. With XP we detected proteins in all the region of the osteoide. The diagnosis of OSA restrains mainly in the morphological analysis of tumor and in this extracellular matrix produced. Commonly, it is made with HE. Here we show an easy and quick approach that is going to obtain more information about the tumor and his matrix, facilitating the diagnosis.
\end{abstract}

Keywords: Osteossacome; Histopathology; Histochemistry; Extracellular matrix.

\section{INTRODUÇÃO}

Apesar de relativamente pouco frequente em relação a outros órgãos e tecidos (1/ 100.000 habitantes/ ano; 1,39\% de todas as neoplasias), os tumores ósseos são muito importantes pelos problemas de diagnósticos e tratamentos que suscitam. Seu diagnóstico não é fácil, exigindo íntima colaboração do clínico, radiologista e patologista, completado quando necessário por análises imuno-histoquímica, bioquímica, além de cintilografia óssea, tomografia computadorizada (CT) e ressonância magnética (MRI), onde possibilitam a avaliação da extensão da lesão dentro do osso e a invasão de partes moles, fazendo parte do tratamento alternativo a amputação $(1,2)$.

0 termo osteossarcoma (OSA) referese aum grupo heterogêneo de neoplasias malignas que afetam a formação de osso ou tecido mesenquimal, sendo caracterizado pela diversidade de aspectos histológicos e de comportamento clínico-biológico (3). O OSA é definido como um tumor mesenquimal primário maligno cujas células cancerosas produzem matriz óssea, sendo o tumor mais comum em ossos respondendo por 20\% dos cânceres ósseos primários em humanos (4). A presença de osteoide distingue o OSA das demais neoplasias ósseas malignas não osteogênicas, sendo este um tumor extremamente agressivo e de crescimento rápido, tanto no local de crescimento quanto na formação de metástases (3, 5-7).

As principais manifestações dos sarcomas ósseos são o aumento de volume, a dor e limitação dos movimentos podendo ser descobertos pela ocorrência de fraturas ósseas patológicas ou em radiografia de rotina (1-2). Em animais domésticos, os tumores ósseos primários ocorrem em cerca de 3 a $4 \%$ de to dos os tumores malignos caninos, sendo descritos em gatos. Em cãos, histologicamente, 85\% desses tumores são osteossarcomas e afetam principalmente animais de grande porte (8). A té hoje nenhum sistema foi aceito como tendo um prognóstico significativo 
ou uma classificação amplamente usada para o OSA, seja em animais ou humanos. Para sua classificação, os dados são baseados nos padrões histológicos, sendo feita uma correlação dentre os subtipos de O SAs direcionando o prognóstico e a terapia aplicada (9).

A classificação do OSA dentro das seis categorias (osteossarcoma pouco diferenciado, osteossarcoma osteoblástico, osteossarcoma condroblástico, osteossarcoma fibroblástico, osteossarcoma talangiectásico, osteossarcoma do tipo células gigantes) é determinada pelo padrão das secreções representativas do tumor, não havendo um padrão isolado dominante. Considerando a importância dos OSAs em humanos, a grande excasses de informações sobre esse tipo de tumor em animais domésticos, a completa ausência de dados sobre animais selvagens, o fato do diagnóstico ser basicamente baseado em dados histopatológicos e que muitas vezes não há consenso nos sistemas de classificação, nós nos propusemos a fazer uma avaliação histológica e histoquímica de OSAs, buscando fornecer informações que possam ser utilizadas para a melhor compreensão da doença, sobretudo em animais.

\section{MATERIAIS E MÉTODOS}

\section{Análise e incidência dos osteossarcomas em animais domésticos}

Foi realizado um levantamento dos casos diagnosticados como osteossarcoma nos arquivos do laboratório de histopatologia do hospital veterinário do Unipinhal. Os dados analisados foram: idade dos animais acometidos, sexo, raça e localização anatômica das lesões ósseas. Nos casos onde o diagnóstico foi feito por análise histopatológica, os blocos foram localizados e separados. Não puderam ser aproveitadas para análise em microscopia de luz as lâminas referentes aos laudos obtidos por exames citológicos, pois estas são descartadas, uma vez que o diagnóstico é estabelecido.

\section{Microscopia de luz - análise morfológica e histoquímica}

D as amostras diagnosticadas como osteossarcoma, obtidas através de biópsias, necrópsias ou cirurgias, foram realizados cortes histológicos com $5 \mathrm{~mm}$ deespessura. Posteriormente as amostras foram coradas com hematoxilina e eosina (HE) e analisadas para avaliação morfológica e confirmação do diagnóstico. Para análise histoquímica, foram realizados novos cortes com a mesma espessura, sendo estes corados com azul de toluidina em pH 4,0 (AT), o xylidine ponceau em pH 2,5 (XP) e azul de alcian em pH 2,5 (AA).

\section{RESULTADOS}

\section{Análise e incidência dos osteossarcomas em animais domésticos}

Quatro casos de cães com OSA foram detectados no período correspondente aos anos de 2003 a 2006, com idades variando de um 1 a 15 anos, apresentando média de 9,5 anos. Quanto ao sexo, houve predominância do sexo masculino (3 machos e 1 fêmea), sendo dois deles sem raça definida (SRD) e dois da raça Rottweiler. As localizações anatômicas das lesões diagnosticadas como O SA ocorreram nas seguintes regiões: primeirapartedo membro superior, região metafisária da tíbia esquerda, ulna distal e um dos casos não consta a localização do tumor nos arquivos. Não foram encontrados registros de casos em animais selvagens, apesar da ocorrência de zoológicos e bosques na região.

Além de confirmaro diagnóstico de O SA, a análise morfológica do material por HE mostrou intensa proliferação celular com acentuado grau de pleomorfismos em algumas amostras (Figura 1A). Foi observado, também, produção de relativa quantidade de matriz osteoide (Figura 1B). Por outro lado, encontramos em alguns casos grande quantidade de matriz osteoide formada, muitas vezes com 0 aprisionamento de células no interior desta mesma matriz (Figuras 1C e 1D). 

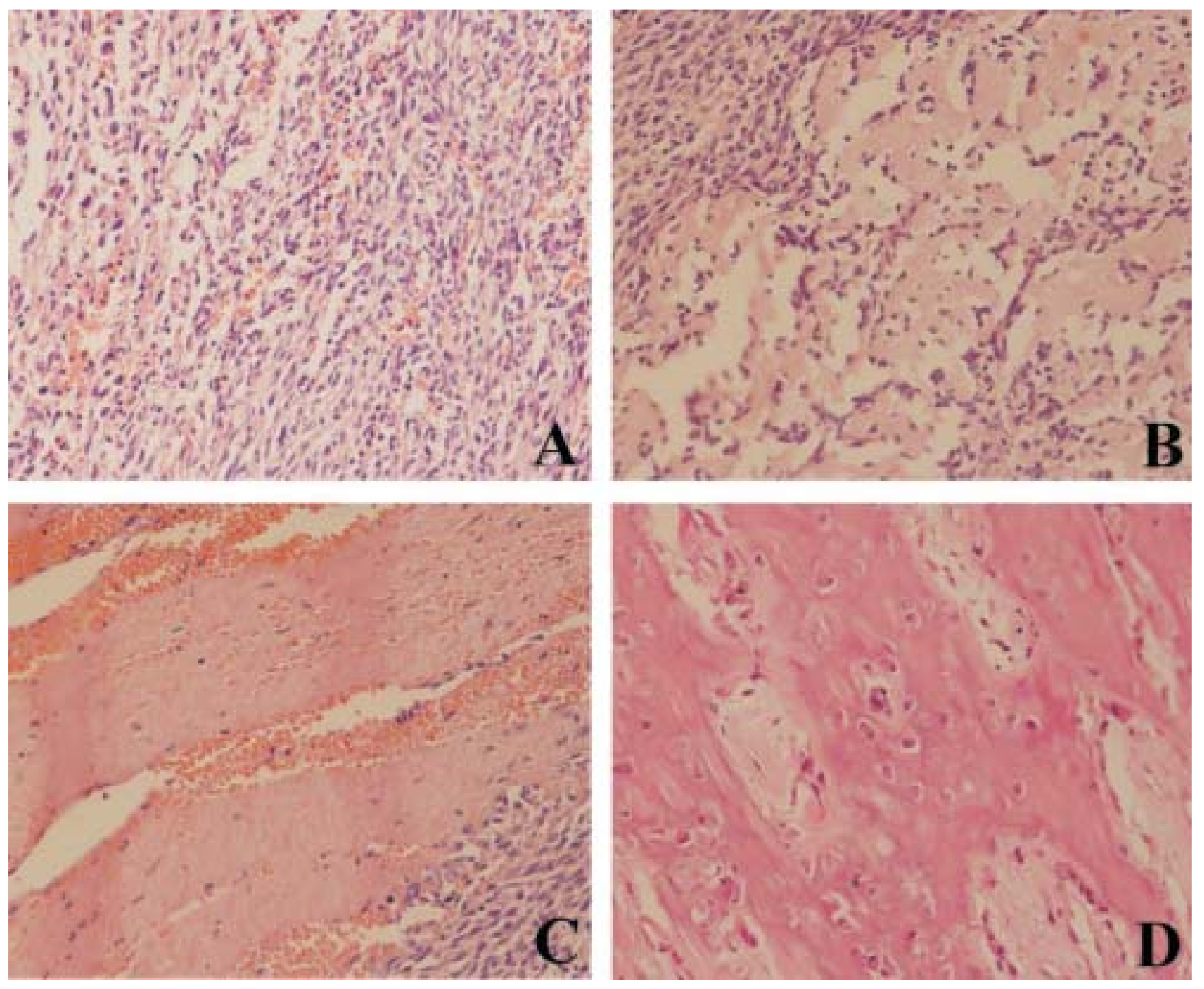

FIGURA 1 - O steossarcoma canino corado com Hematoxilina e Eosina. Em A) região de proliferação celular; B) produção de osteoide; C) e D) regiões onde se observam grande quantidade de matriz óssea formada. Aumento final: 200X para D e 100X para as demais figuras

Com a utilização do AT também encontramos a existência de uma grande área de proliferação celular e, ao redor das células, foi encontrada grande quantidade de glicosaminoglicanos. Nestes casos, os núcleos se mostraram fortemente basófilos (Figura 2A). Onde se observa osteoide formado (Figuras 2B e 2D), a quantidade de glicosaminoglicanos diminui significativamente. Foi observado ainda que, em algumas regiões, estão presentes células cartilaginosas (Figura 2C), onde se encontra grande basofilia metacromática, indicando uma concentração maior de glicosaminoglicanos que nas demais amostras estudadas. O sresultados obtidos com o AA mostram equivalência com os do AT. Com o AA é observada grande quantidade de glicosaminoglicanos nas amostras em proliferação (Figura 3A) e ao redor de porções de cartilagem normal, próximo aos tumores (Figura 3C). Por outro lado, nas regiões com formação de matriz osteoide, é encontrada uma redução nessa quantidade de glicosaminoglicanos (Figuras 3B e 3D ), onde a matriz osteoide se mostrou pobre nesses componentes. Com acoloração XP foipossível observarquantidades elevadas de proteínas totais sintetizadas pelas células 
neoplásicas, apresentando aumento considerável dessas proteínas envolvendo a região onde se encontram as células cartilaginosas (Figura 4C) e, principalmente, em toda a região da matriz osteoide (Figura 4D ). Nas regiões onde se observam células em proliferação (Figura 4A) é observado grande quantidadedenúcleosfortementeacidófilo.À medida que ocorre a formação de matriz osteoide, observase a separação das células e a deposição de proteínas próximas a elas (Figura 4B).
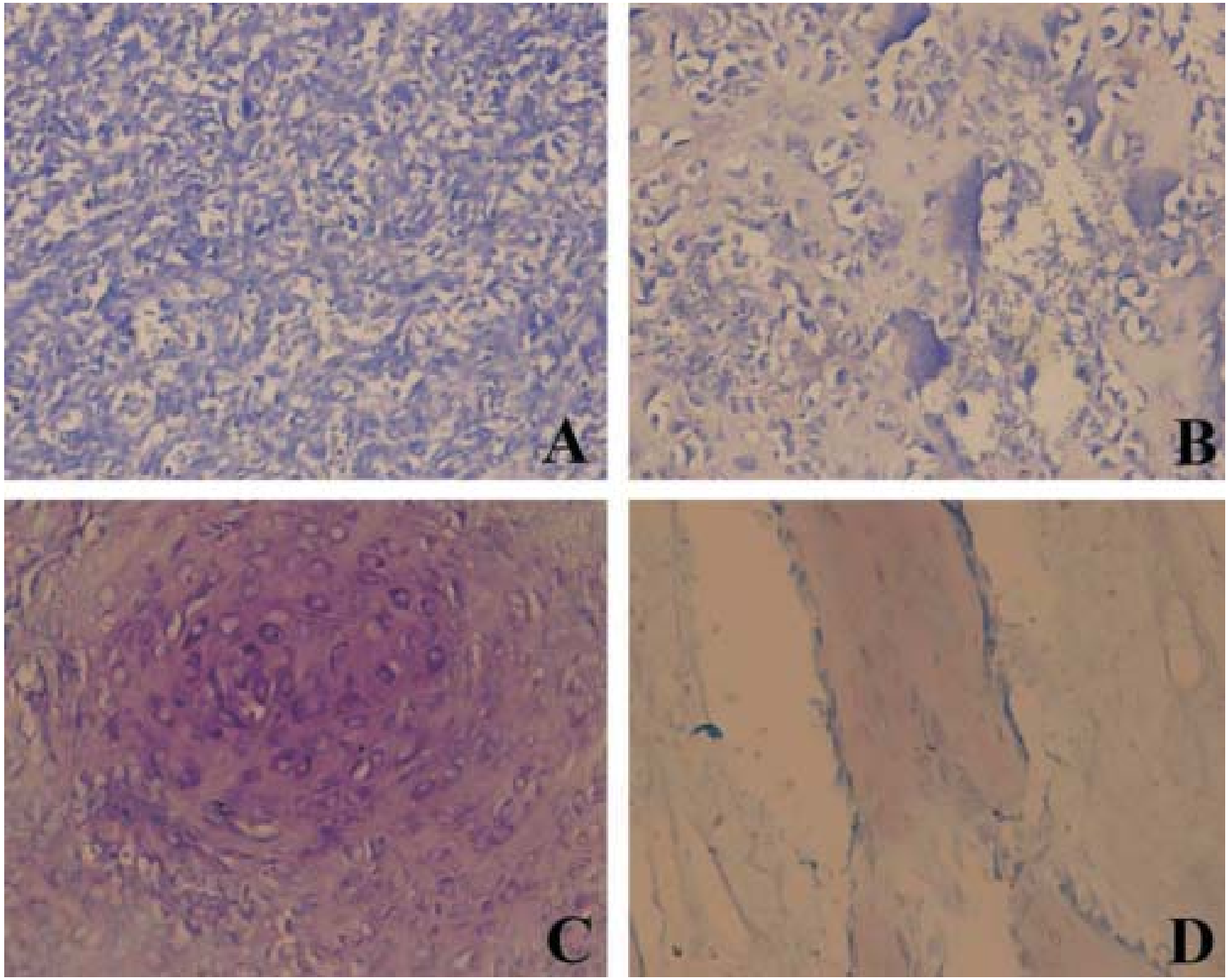

FIG URA 2 - O steossarcoma canino corado com Azul de Toluidina em pH 4.0. Em A) região de proliferação celular; B) produção de osteoide; C) região de células cartilaginosas; D) região onde se observa grande quantidade de matriz óssea formada. Aumento final: 100X para A e 200X para as demais figuras 

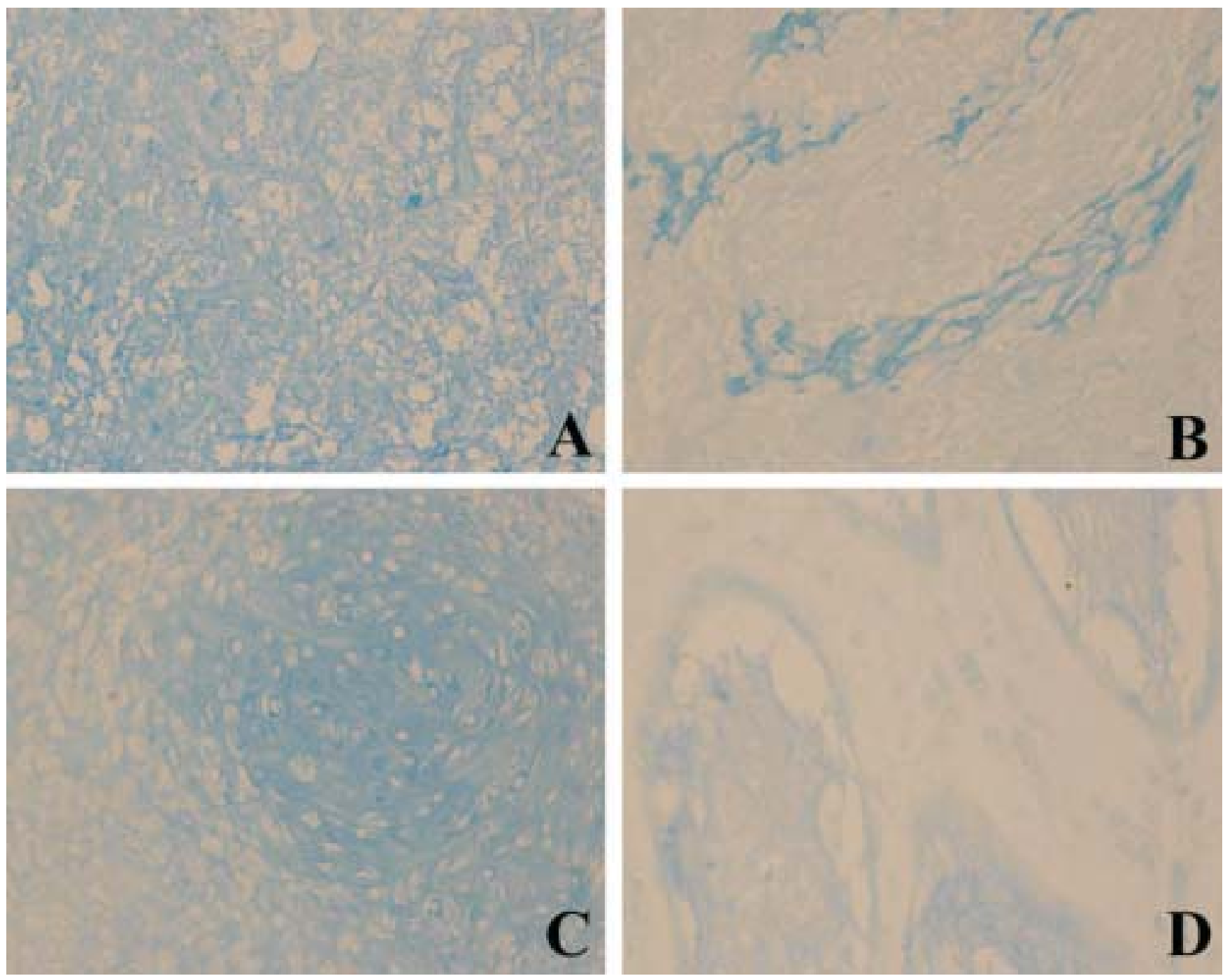

FIGURA 3 - O Osteossarcoma canino corado com Azul de Alcian em pH 2,5. Em A) região de proliferação celular; B) produção de osteoide; C) região de células cartilaginosas; D) região onde se observa grande quantidade de matriz óssea formada. Aumento final: 200X 

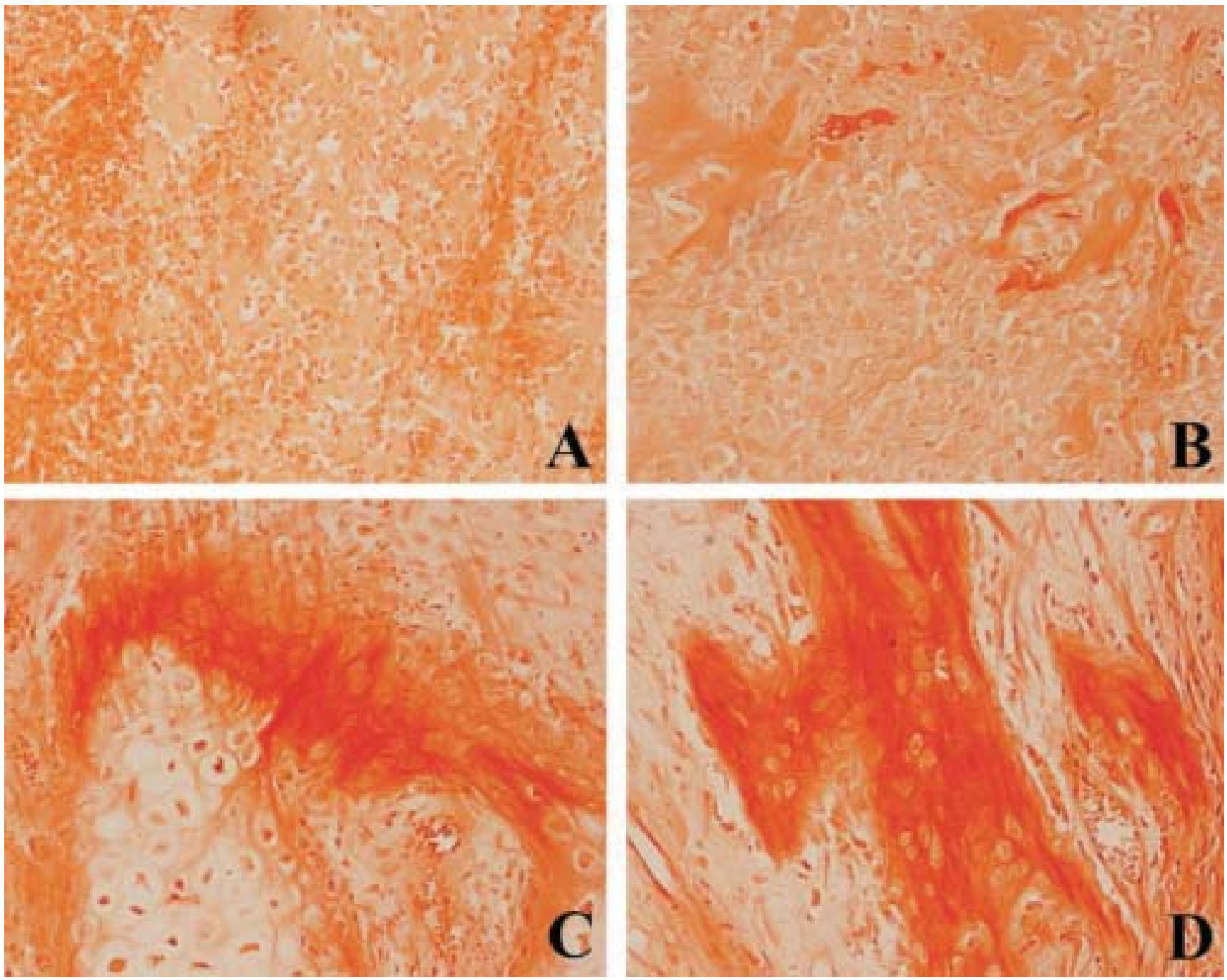

FIGURA 4 - O steossarcoma canino corado com Xylidine Ponceau em pH 2,5. Em A) região de proliferação celular; B) produção de osteoide; C) região de células cartilaginosas; D) região onde se observa grande quantidade de matriz óssea formada. Aumento final: 100X para A e 200X para as demais figuras

\section{DISCUSSÃO}

O OSA é um tumor mesenquimal maligno de células ósseas primitivas que se caracteriza pela produção de osteoide $(10,11)$. É pouco frequente em animais domésticos, daí o relativo desintesse em seu estudo pelo clínico veterinário. Existem várias subclassificações histológicas, baseadas no tipo e quantidade de matriz óssea e nas características, não sendo observada diferença em relação ao comportamento biológico entre esses subgrupos em cães $(12,13)$. D evido à natureza multipotencial das células mesenquimais primitivas, a matriz envolvida nestes tumores pode conter variadas quantidades de tecido cartilaginoso, colágeno e osteoide, mesmo assim esse tumor pode ser diagnosticado como O SA, refletindo, dessa forma, o potencial maligno de tumores mesenquimais com potenciais osteogênicos $(2,7)$. A presença de células mesenquimais malignas, produzindo uma matriz de tecido fibroso ou cartilaginoso antes de osteoide, não exclui a possibilidade de OSA, especialmente se a lesão está num local de predileção conhecida $(2,7)$. Porém, somente o OSA produz matriz osteoide $(2,7)$.

Em animais domésticos, o OSA é a neoplasia óssea primária mais frequentemente diagnosticada em cães $(13,14)$ representando de $3 \%$ a $4 \%$ de todos os tumores malignos $(8,12)$. Em 
humanos, o O SA pode ocorrer em todas as faixas etárias, mas apresenta com uma distribuição bimodal, sendo que $75 \%$ desse tumor acometem pacientes menores de 20 anos, o segundo e menor pico ocorre nos idosos. No total, os homens são mais afetados que as mulheres, na proporção de 1,6:1 (4), sendo representado por 5\% das doenças malignas na infância e adolescência (15). 0 tempo médio de diagnóstico varia em torno de 5 meses (16). Em animais, a literatura demonstra maior ocorrência de OSA em cães adultos (6), com uma média de idade de 7,5 anos $(7,12)$, podendo ocorrer em animais de todas as idades. No presente estudo foi observado o desenvolvimento de OSA em diferentes idades, apresentando uma mediana de 9,5 anos com um predomínio de indivíduos adultos.

Apesar de termos uma amostragem pequena, todos os casos levantados por nós mostraram que, quanto ao sexo, houve prevalência de indivíduos do sexo masculino. Esses resultados corroboram com os dados descritos por $\mathrm{D}$ aleck et al. (7) e Siqueira e Cavalcanti (14), que mostraram uma maior incidência de OSA em cães machos. Em estudo recente realizado por Rech et al. (15), novamente foi observado um predomínio de OSA em humanos do sexo masculino.

Com respeito à distribuição anatômica, a literatura relata um predomínio de OSA afetando 0 esqueleto apendicular (13), sendo esses dados confirmados por Cavalcanti et al. (6) e por D aleck et al. (7) que relatam que 75\% dos O SAs desenvolvemse no esqueleto apendicular e $25 \%$ têm origem no esqueleto axial e crânio. Nossos dados mostraram que os OSAs encontrados localizavam-se sempre no esqueleto apendicular, entretanto em pontos específicos diferentes. D esta forma, não foi possível estabelecer uma relação entre o ponto de ocorrência do tumor com a raça dos animais estudados.

Muitos OSAs desenvolvem-se em locais de maior crescimento ósseo, onde apresenta aumentada a atividade mitótica (4). Na espécie humana, 70\% dos sarcomas osteogênicos ocorrem nos membros inferiores, os quais suportam maior peso corporal e são expostos a pequenos traumas (14), porém, é importante observar que, embora 0 traumatismo possa chamar a atenção para um O SA existente, não há evidência de que provoque 0 tumor (17). Cães de raças grandes ou gigantes como São Bernardo, Boxer, D inamarquês, Pastor Alemão estão sob maior risco de desenvolvimento de OSA, acometendo principalmente os membros torácicos, devido a ter de suportar maior peso corpóreo (7). A região metafisária dos ossos longos é o sítio primário mais acometido pelo OSA em cães (13) e em humanos, apresentando ocorrência de aproximadamente $60 \%$ ao redor do joelho $(4,13)$.

Em análise histopatológica as colorações com HE são rotineiramente utilizadas para evidenciar a morfologia das células e tecidos. O bservamos diferentes padrões de O SA em nosso estudo. Um desses padrões mostrava uma intensa área de proliferação celular com um acentuado grau de pleomorfismo. Em outro padrão, observamos a síntese de matriz osteoide preenchendo grandes áreas, afastando células umas das outras, com 0 aprisionamento de algumas células cancerosas no interior dessa matriz, sendo esses resultadostambém descritos por outros autores em animais domésticos $(6,9,14)$. Finalmente observamos regiões onde se observa matriz osteoide abundante. Somente 0 OSA produz esse tipo de matriz $(7,8)$.

Interessante ressaltar que os achados histopatológicos condizentes com os osteossarcomas são muito semelhantes ao observados em outras patologia com alteração na ossoficação (17). A ossificação de cartilagem brônquica em processos cicatriciais é um processo relativamente comum; mas, formas difusas de ossificação são raras. Entretanto, existem algumas formas de ossificação pulmonar dendriforme que são muito semelhantes histologicamente aos O SAs. D a mesma maneira, são mais frequentemente encontradas em homens do que em mulheres (18). Os níveis séricos de cálcio, fósforo e fosfatase alcalina são normais. A patogênese é desconhecida. Algumas teorias têm sido descritas tentando explicar o achado de tecido ósseo no parênquima pulmonar. A interação de fibroblastos intersticiais e fibrinas e plaquetas intralveolares, em um meio ácido anóxico, que exsudam para o espaço interalveolar, devido à destruição e alteração da permeabilidade dos capilares alveolares, resultaria em metaplasia de fibroblastos para osteoblastos com a subsequente transição de colágeno para matriz óssea (19).

Alterações em tecidos cartilaginos seguem o mesmo padrão. Com a idade, cartilagens elásticas têm pequena tendência à calcificação, mas não ossificação, no entanto, as cartilagens hialinas apresentam certo nível de ossificação. A cartilagem tireóidea sofre ossificação endocondral com o passar 
do tempo. Uma vez mais, o grau de ossificação é menor no sexo feminino (20). Ao que parece, distúrbios de ossificação possuem uma predileção, ainda não explicada, pelo sexo masculino. Histologicamente, os achados em ossificações de cartilagem traqueal são semelhantes, embora não iguais, ao observados em osteossarcomas.

Através do AT foi possível obtermos um pouco mais de informações sobre a atividade dos OSAs. O AT é um corante básico, que em pH 4,0, que se liga em grupos $\mathrm{PO}_{4}$; $\mathrm{SO}_{4}$; $\mathrm{COO}^{-}$presentes em DNA, RNA e glicosaminoglicanos $(21,23)$. Os resultados obtidos com esse corante mostram grandes quantidades de glicosaminoglicanos em meio às células em proliferação, mas a matriz osteoide mostrou-se pobreem glicosaminoglicanos, com uma leve basofilia ortocromática. Foi observado, também, regiões com presença de células cartilaginosas normais na região epifisária. Nestas regiões, observamos um basofilia metacromática muito intensa, indicando a abundância de glicosaminoglicanos nela, condizente com um tecido cartilaginoso normal. Nossos dados mostram que a quantidadede glicosaminoglicanos diminui àmedida que é formada a matriz osteoide pelo OSA.

Segundo Meuten (9), em um O SA do tipo condroblástico pode ocorrer produção de matrizes osteoides e condroides pelas células mesenquimais malignas, ou ocorrer uma interjunção do osso e de elementos de cartilagens produzidos por estas células neoplásicas. Rubin e Farber (17) relatam que, com frequência, focos de células de cartilagem maligna ou células gigantes podem estar presentes entre o tecido ósseo. Não observamos nenhum desses padrões em nosso material.

O AA também é um corante básico, que em $\mathrm{pH} 2,5$, cora somenteos grupos $\mathrm{SO}_{4}$ eCO O presentes em glicosaminoglicanos $(21,23)$. Com esse tipo de coloração, foi observada uma equivalência dos dados obtidos através com AT. O XP éum coranteácido que cora radicais positivos $\mathrm{NH}_{3}{ }^{+}$, que em $\mathrm{pH}$ 2,5 são encontrados em proteínas totais $(21,23)$. O s resultados observados através dessa coloração definem quantidades elevadas de proteínas envolvendo as regiões onde encontramos células cartilaginosas. Notamos uma grande acidofilia nos OSAs, principalmente em toda a região de matriz osteoide.

Devido à natureza multipotencial dessas células mesenquimais primitivas, a matriz do tumor pode conter quantidades variadas de cartilagem, colágeno e osteoide (9). A matriz óssea é composta por $90 \%$ de colágeno do tipo 1 do osteoide e por outras proteínas ósseas adicionais (24). Por outro lado, embora o tecido cartilaginoso possua uma matriz que apresente fibrilas de colágeno II, 0 componente mais abundante são proteoglicanos $(24,25)$. Essas características histológicas são compatíveis com os dados histoquímicos que relatamos.

Porções filamentosas de osteoide podem lembrar tecido fibroso rico em colágeno $(6,9)$, sendo esta proteína a mais abundante nessa matriz osteoide. O colágeno pode ser evidenciado juntamente com outras proteínas não colagênicas da matriz através do XP.A formação óssea ocorre por síntese e secreção de matriz óssea orgânica pelos osteoblastos, a qual, em pouco tempo, sofre mineralização $(24,25)$. Na osteogêneseintramembranosaas célulasmesenquimais se agregam e adquirem morfologia de osteoblastos, que passam a secretar matriz óssea, formando os centros de ossificação. Mais adiante 0 íon cálcio é transportado por vasos sanguíneos e depositado sobre a matriz, fazendo com que ocorra a mineralização e formação do tecido ósseo primário $(24,25)$.A ocorrência de uma proliferação descontrolada de células mesenquimais primitivas malignas com diferenciação osteoblásticas e produção de osteoide podem dar origem ao sarcoma osteogênico (7). Em pacientes sem metástases, existe uma correlação direta entre o tempo de sobrevida e o índice de proliferação celular (26).

\section{CONCLUSÕES}

Durante a ossificação, um evento que inicia o processo éa deposição de glicosaminoglicanos. Com a produção de colágeno, e decorrente mineralização, ocorre a remoção dos glicosaminoglicanos. Durante esse processo, um evento-chave é a produção da enzima fosfatase alcalina. (27). Neste trabalho, observamos O SA em diferentes níveis de produção de osteoide. O bservamosumagrandeprodução deglicosaminoglicanos precedendo a formação do osteoide mas, quando este se forma, a taxa de glicosaminoglicanos decai de forma significativa. Assim, podemos estabelecer aqui um paralelo entre a ossificação intramembranosa normal e a formação do osteoide nos OSAs. Mais importante, pelos dados mostrados na literatura esse padrão se assemelha a outras patologias relacionadas com a ossificação. 


\section{REFERENCIAS}

1. Brasileiro Filho G. Bogliolo Patologia. $6^{\text {a }}$ ed. Rio de Janeiro: G uanabara Koogan; 2000.

2. Wittig JC, Bickels J, Priebat D, Jelinek J, Kellar-Graney K, Shmookler B, et al. O steosarcoma: a multidisciplinary approach to diagnosis and treatment. A merican Family Physician. 2002;65:1123-32.

3. Soares RC, Soares AF, Souza LB, Santos ALV, Pinto LP. O steossarcoma de mandíbula inicialmente mimetizando lesão do periápice dental: relato de caso. Revista Brasileira de O torrinolaringologia. 2005;171:242-5.

4. Kumar V, Abbas AK, Fausto N. Robbins e cotran patologia - Bases patológicas das doenças. $7^{\text {a }}$ ed. Rio de Janeiro: Elsevier; 2005.

5. Bastos TM, Serafini OA, Barrios CHE, Velasco PA. O steossarcoma: tratamentos e fatores prognósticos. Revista Brasileira de O rtopedia. 1999;34:59-62.

6. Cavalcanti JN, Amstalden EMI, Guerra JL, Magna LC. O steosarcoma in dogs: clinicalmorphological study and prognostic correlation. Brazilian Journal of Veterinary Reserarch and Animal Science. 2004;41:299-305.

7. Daleck CR, Fonseca CS, Canola JC. O steossarcoma canino - revisão. Revista de Educação Continuada CRMV. 2002;5:233-42.

8. Daleck CR. Osteossarcoma canino. Clínica Veterinária. 1996;1:26-7.

9. Meuten DJ. Tumors in domestic animals. $4^{\mathrm{a}}$ ed. Iowa: State Press; 2002.

10.Lima MA, Rivas LG, G recco MAS, D rumond JMN. O steossarcoma extra-esquelético primário da região frontal. Revista de Assistência Médica Brasil. 1998;44:43-6.

11. Tossato PS, Pereira AC, Cavalcanti MGP. Osteosarcoma and chondrosarcoma radiographic differentiation by means of computed tomography. Pesquisa O dontológica Brasileira. 2002;16:69-6.
12. Costa FS, Tostes RA, Farias MR, Sampaio RL, Perez JA. Metástase cutânea de osteossarcoma em um cão - relato de caso. Brazilian Journal of Veterinary Research and Animal Science. 2001;38:240-2.

13. Power BE, Straw RC, Withrow SJ. Management of canine appendicular osteosarcoma. Veterinary Clinics of North America. 1990;20:1141-58.

14. Siqueira VJW, Cavalcanti JN. O steossarcoma pós-fratura umeral em um cão - relato de um caso. Revista Cães \& Gatos. 1993;8:04-6.

15. Rech A, Castro Jr CG, Mattei J, G regianin L, Di Leone L, D avid A, et al. Características clínicas do osteossarcoma na infância e sua influência no prognóstico. Jornal de Pediatria. 2004;80:65-70.

16. Guerra RB, Tostes MD, Miranda LC, Camargo OP, Baptista AM, Caiero MT, et al. Comparative analysis between osteosarcoma and Ewing's sarcoma: evaluation of the time from onset of signs and symptoms until diagnosis. Clinics. 2006;61:(2)99-106.

17. Rubin E, Farber JL. Patologia. 6a ed. Rio de Janeiro: G uanabara Koogan; 2002.

18. D uarte AAO, Nakatani J, Rigueiro MP, Saad T. O ssificação pulmonar dendriforme. Jornal Brasileiro de Pneumologia. 2006;32:270-3.

19. Ikeda $Y$, Yamashita $H$, Tamura T. D iffuse pulmonary ossification and recurrent spontaneous pneumothorax in a patient with bronquial asma. Respiratory Med. 1998;92:887-889.

20.Cruz WP, Dedivitis RA, Sementilli A, Rapoport A. Estudo histológico da ossificação da cartilagem tireóidea. Revista Brasileira O torrinolaringologia. 2003;69:734-8.

21. Lison L. Histochemie et cytochemie animales - principles et methodes. Paris: Gauthier Villars; 1960.

22. Módis L. O rganization of the extracellular matrix: a polarization microscopy approach. Boca Raton: CRC Press; 1991. 
23. Mello MLS. Cytochemistry of DNA, RNA and nuclear proteins. Brazilian Journal of Genetics. 1997;20:257-264.

24.Young B, Lowe J, Stevens A, Heath JW. Histologia funcional: texto e atlas em cores. $5^{\mathrm{a}}$ ed. Rio de Janeiro: Elsevier; 2007.

25. Kierzenbaum AL. Histologia e biologia celular: uma introdução à patologia. Rio de Janeiro: Elsevier; 2004.

26. Marinho LC, Patrício FRS, Jesus-Garcia Filho R, Petrilli AS, Odashiro LN, Macedo C, Alves MTS. Clinicopathologic study and Ki67 proliferative marker evaluation in human osteosarcomas. Jornal Brasileiro de Patologia Médica e Laboratorial. 2005;41:419-24.

27. Moreira PL, An YH, Santos Jr AR, Genari $\mathrm{SC}$. In vitro analysis of anionic collagen scaffolds for bone repair. Journal of Biomedical Materials Research - Part B: Appl Biomater. 2004;71B:229-37.

Recebido: 10/ 01/ 2007

Received: 01/ 10/ 2007

Aprovado: 15 / 02/ 2007

A pproved: 02/ 15/ 2007 